Cahiers $d u$ MONDE RUSSE

\section{Cahiers du monde russe}

Russie - Empire russe - Union soviétique et États indépendants

45/3-4 | 2004

Varia

\title{
Matthew Evangelista, The Chechen wars
}

\section{Silvia Serrano}

\section{OpenEdition \\ Journals}

Édition électronique

URL : https://journals.openedition.org/monderusse/4225

DOI : $10.4000 /$ monderusse. 4225

ISSN : $1777-5388$

\section{Éditeur}

Éditions de l'EHESS

\section{Édition imprimée}

Date de publication : 1 juillet 2004

Pagination : 755-757

ISBN : 2-7132-2009-2

ISSN : $1252-6576$

\section{Référence électronique}

Silvia Serrano, "Matthew Evangelista, The Chechen wars », Cahiers du monde russe [En ligne], 45/3-4 I 2004, mis en ligne le 03 juin 2009, consulté le 02 septembre 2022. URL : http://

journals.openedition.org/monderusse/4225; DOI : https://doi.org/10.4000/monderusse.4225

Ce document a été généré automatiquement le 2 septembre 2022

Tous droits réservés 


\title{
Matthew Evangelista, The Chechen wars
}

\author{
Silvia Serrano
}

\section{RÉFÉRENCE}

Matthew EVANGELISTA, The Chechen wars. Will Russia go the way of the Soviet

Union? Washington, D.C., Brookings Institution Press, 2002, 244 p.

1 Alors que, la guerre se poursuivant, la Tchétchénie devient un enjeu, certes faible, mais récurrent sur la scène internationale, la bibliographie qui lui est consacrée s'est considérablement enrichie ces dernières années. Pourtant, la plupart des études portent sur une période antérieure à la reprise des opérations en 1999, y compris l'ouvrage de Valery Tishkov publié en 2004, Chechnya : life in a war-torn society ${ }^{1}$. Le livre de Matthew Evangelista The Chechen wars. Will Russia go the way of the Soviet Union? est donc le premier à aborder les deux guerres. Une large part est faite au risque d'implosion de la Russie, question centrale qui anime tout l'ouvrage, même si d'emblée l'auteur y répond par la négative.

Dans la première partie, M. Evangelista revient sur le déroulement des événements, depuis 1994 jusqu'à la reprise des opérations militaires en 1999, après trois ans de «ni guerre ni paix » (d'où le titre du chapitre 3 ). Le deuxième chapitre est particulièrement éclairant en ce qu'il montre qu'en dépit des causes déjà connues (arguments stratégiques, héritage soviétique, mémoire historique et nationalisme tchétchène), la première guerre était surtout le fruit de logiques conjoncturelles. Le recours à des sources récentes, notamment aux mémoires de neuf anciens conseillers de $\mathrm{El}^{\prime}$ cin et d'un ancien ministre de Dudaev, permet de préciser ce que la guerre doit à ces deux personnalités et à la faiblesse du "camp de la paix ». L'évolution des relations russo-tchétchènes et les divisions internes, après les accords de Kassav-Iurt, aboutissent à la reprise des opérations. Le chapitre 4 revient sur les zones d'ombre qui entourent le déclenchement de la seconde guerre, dans le contexte de la succession de Boris El'cin. 
3 La seconde partie du livre est consacrée à une discussion sur le fédéralisme russe, alors que l'argument d'une fragilité de l'État est abondamment mis en avant par les hommes politiques comme justification de la guerre. Le parallèle avec le Tatarstan est fréquemment évoqué, mais souvent de manière superficielle; l'auteur fait ici une comparaison approfondie entre différentes régions où existait un risque sécessionniste potentiel (Tatarstan, mais aussi Daghestan, Bachkortostan, Extrême-Orient), pour conclure à la spécificité du cas tchétchène (chapitre 5). Il montre que les autorités russes ont surestimé la menace d'une implosion de la Russie et la faiblesse du « fédéralisme asymétrique ", les remèdes proposés par Putin - le renforcement de la verticale du pouvoir et de la « dictature de la loi »- se révélant, à son sens, plus dangereux que le mal lui-même (chapitre 6).

4 Enfin, M. Evangelista étudie les conséquences des guerres en Tchétchénie sur la posture internationale de la Russie. Il souligne que, face aux violations massives et avérées du droit international, la communauté internationale a réagi avec passivité (chapitre 7), faisant montre d'une grande bienveillance envers Putin, dès son accession à la présidence. Cela l'amène à relativiser les conséquences du 11 septembre 2001 (chapitre 8) dans la mesure où, déjà auparavant, la volonté de coopérer avec la Russie prévalait. L'auteur conclut que, s'il est improbable que la Russie subisse le sort de l'URSS, il ne faut en revanche pas sous-estimer les conséquences à long terme de la guerre sur l'ensemble de la société russe.

5 Le livre est remarquablement documenté, l'ensemble des sources secondaires, journalistiques ou mémoires, étant sollicité. Qu'il s'agisse du positionnement des acteurs du conflit, de la comparaison entre les sujets de la Fédération potentiellement sécessionnistes, ou de l'examen des instruments du droit international permettant de qualifier les violations, la rigueur et le retour méticuleux aux textes permettent quelques salutaires inflexions par rapport aux analyses généralement admises : ainsi les déclarations de Dudaev affirmant, en avril 1993, qu'il se considérait toujours comme un citoyen de la Fédération russe, enjoignent de préciser la nature de l'indépendantisme tchétchène.

6 On peut regretter que quelques témoignages importants soient absents de l'ouvrage, parce que parus plus tardivement, notamment les mémoires de R. Hasbulatov, du chirurgien tchétchène $\mathrm{H}$. Baev, et du combattant islamiste américain enrôlé dans la résistance A.Collins, qui apportent un éclairage nouveau sur la guerre vue de Tchétchénie, par des officiels, des civils ou des combattants. Ils permettent de compenser, même très légèrement, le déséquilibre entre sources russes et sources tchétchènes. Là n'est pas le moindre écueil auquel chacun est confronté dès lors qu'il s'agit de travailler sur la Tchétchénie. Des entretiens avec des acteurs ou des témoins tchétchènes peuvent contribuer à compenser ce déséquilibre, mais ce n'était pas là l'objectif de M. Evangelista, qui choisit d'étudier les guerres à l'aune de l'évolution politique russe sous le gouvernement de El'cin, puis sous celui de Putin.

7 En conséquence, la dimension interne est pratiquement absente, notamment dans les chapitres consacrés à la seconde guerre, illustration de la difficulté grandissante à accéder à des sources tchétchènes, dans un contexte de reprise en main de la presse et d'isolement accru. On peut être reconnaissant à M. Evangelista d'opposer aux commentaires trop souvent dominés par l'émotion une analyse rigoureuse et argumentée. Mais il a tendance à surestimer les rationalités à l'œuvre, et à ne pas donner tout son poids au rôle des représentations. Ainsi, si le risque d'effet domino était exagéré, 
voire, de l'ordre du fantasme, il n'en est pas moins agissant : non seulement les autorités russes, mais également une large part de la société civile ont accepté la guerre parce que, traumatisée par l'effondrement de l'URSS, cette société était fragilisée dans son identité. De même, l'auteur a raison de voir dans l'islam un déterminant marginal du conflit. Il n'en reste pas moins que, en raison d'un jeu de représentations croisées rendues possibles par un environnement international ouvert, le prisme islamiste, même s'il est invoqué à tort, tend à déterminer les positionnements en s'imposant peu à peu à l'ensemble des acteurs : aux autorités russes qui ont tout intérêt à mettre en avant la convergence d'intérêts dans la lutte contre le « terrorisme islamiste international », à la communauté internationale qui voit là une justification a posteriori de son soutien à Moscou, et enfin à bon nombre des Tchétchènes eux-mêmes, qu'ils soient sommés de prouver qu'ils ne sont pas des terroristes islamistes ou qu'ils espèrent que le recours à une imagerie islamiste leur gagnerales soutiens que l'Occident leur refuse.

8 Ces quelques réserves n'enlèvent rien à l'intérêt d'un ouvrage qui vient stimuler la réflexion sur un conflit qui risque d'être durablement un déterminant majeur des évolutions politiques et sociales russes.

\section{NOTES}

1. Berkeley, University of California Press, $284 \mathrm{p}$. 